\title{
The Association of Depression and Sense of Belonging with Suicidal Ideation Among Older Adults: Applicability of Resiliency Models
}

\author{
Suzanne McLaren, BA(Hons), PhD, \\ Rapson Gomez, BSc(Hons), DipAppChdPsych, MSc, PhD, Maria Bailey BA(Hons), \\ and Renee K. Van Der Horst, BPsych, PostGradDip Psych
}

Suicide among older people, especially men, is a significant problem. In this study the applicability of the compensatory, the risk-protective, the challenge, and the protective-protective models of resiliency for the prediction of suicidal ideation from depression (the risk factor) and sense of belonging to the community (the protective factor) was investigated. A total of 351 retired Australians (130 males and 221 females), with a mean age of 71.31 years $(S D=7.99)$, completed the Zung Depression Scale, the suicide subscale of the General Health Questionnaire, and the Sense of Belonging Instrument. When sense of belonging (psychological) was the protective factor, results indicated support for the risk-protective model for men and women, and for the compensatory model for women only. In contrast, when sense of belonging (antecedents) was the protective factor, support was evident for the compensatory model for men and women, and for the challenge model for women only. Results indicate that interventions should be developed to enhance sense of belonging among aging adults.

Suicide is a significant mental health issue among older adults, particularly males (Pritchard \& Hansen, 2005). The most recent statistics indicate that the age-standardized suicide rate for Australian males is $\mathbf{1 7 . 7}$ per 100,000 , which is lower than males aged 65 to 74 years $(19.4$ per 100,000$)$ and over 75 years (22.9 per 100,000) (Australian Bureau of Statistics, 2004). Research has indicated that suicidal ideation is a predictor of suicide

Suzanne McLaren, Rapson Gomez, Maria Bailey, and Renee Van Der Horst are with the School of Behavioural \& Sciences \& Humanities at the University of Ballarat in Australia.

Address correspondence to Dr. Suzanne McLaren, School of Behavioural \& Social Sciences \& Humanities, University of Ballarat, University Drive, Mt Helen Vic 3353, Australia; Email: s.mclaren@ballarat.edu.au attempts and completions (Mireault \& de Mann, 1996). Identifying predictors of suicidal ideation in older adults should lead to an improved understanding of suicide risk in this age group.

Depression is a key risk factor for suicidal ideation and suicide completions in older adults (Awata et al., 2005; Preville, Boyer, He Bert, Bravo, \& Seguin, 2005). A range of factors have been implicated in the development of depression among aging people, including poor physical health (Tsuboi, Fukukawa, Niino, Ando, \& Shimokata, 2004), income (Schulz, Tompkins, \& Rau, 1998), disability (Yang, Haley, \& Small, 2002), cognitive impairment (Lockwood, Alexopoulos, \& Kakuma, 2000), and social support (Besser \& Priel, 2005). It is evident, however, that not all depressed older people suicide or contemplate suicide. It would seem 
that protective factors operate that prevent some elderly from suicide, despite being depressed.

One possible protective factor is a sense of belonging to the community. Belonging is a basic human need (Maslow, 1954), necessary for psychological well-being and self-actualization (Chubb \& Fertman, 1992). It is evident that humans are primarily social animals, favoring group living and meaningful contact with others (Brewer, 1991). A lack of human interaction may impact on an individual's formation of a personal identity and can affect every aspect of their lives, from their personal development through to social relationships, mental health, and sense of belonging (Hagerty, Lynch-Sauer, Patusky, Bouwsema, \& Collier, 1992).

A sense of belonging is an extension of Maslow's (1954) concept of belongingness and it is what connects individuals with their surrounding people and environment. Hagerty et al. (1992) have defined sense of belonging as the experience of being both personally involved and integrated within an environment or system. In order for an individual to experience a sense of belonging two important dimensions are essential. First, the individual has to have the energy, interest, and potential to develop a sense of belonging (antecedent dimension). Second, once this is achieved, they have to feel valued, needed, and significant within their environment (psychological dimension) (Hagerty et al., 1992; Hagerty, Williams, Coyne, \& Early, 1996).

Sense of belonging appears necessary for psychological well-being (ThompsonFullilove, 1996). Studies have shown that low sense of belonging may result in higher levels of anxiety and associated disorders (Herbert, 1997; Lee \& Robbins, 1998), depression (Hagerty et al., 1996; McLaren, Jude, Hopes, \& Sherritt, 2001), and suicidal ideation (Bailey \& McLaren, 2005). Although there has been little research on sense of belonging in older people, the limited available evidence indicates that lower levels of belonging to the community are associated with higher levels of depression and suicidal ideation among retirees (Bailey \& McLaren, 2005) and fewer reasons to live (Kissane \& McLaren, 2006).

It was noted earlier that not all depressed people suicide or contemplate suicide, and that sense of belonging to the community may play an important role in this respect. If this view is accepted then it will be useful to examine the processes involved. It is argued here that resiliency models proposed for evaluating the relationships of risk and protective factors with adjustment can provide useful insights on the protective role of sense of belonging in the relation between depression and suicidal ideation. To date, there are at least four generic resiliency models; namely, the compensatory model, the risk-protective model, the challenge model, and the protective-protective model (Garmezy, Masten, \& Tellegen, 1984; HollisterWagner, Foshee, \& Jackson, 2001; Masten et al., 1988). The compensatory model suggests that the risk and protective factors have additive effects on maladjustment. The risk-protective model suggests that maladjustment is related to the interaction involving the risk and protective factors. More specifically, relative to low levels of the protective factor, higher levels of the protective factor will have more buffering effects on the relation between the risk factor and maladjustment. The challenge model implicates a curvilinear relation between risk and maladjustment, such that a certain moderate amount of the risk factor is seen as enhancing better adjustment. This model assumes that at such levels of the risk factor, protective factors are activated, thereby reducing the potential impact of the risk factor. The protective-protective model suggests that maladjustment is related to the interaction between the risk factor and the number of relevant protective factors that are present. The model predicts that the relationship between the risk factor and maladjustment weakens as the number of protective factors increases.

It is to be noted that these resiliency 
models have been tested using child and adolescent samples only. Studies with children have examined stress exposure (risk factor); school competence (adjustment); and a range of protective factors, including intelligence, socioeconomic status, and family qualities (Garmezy et al., 1984; Masten et al., 1988). Others have examined resiliency models with adolescents. For example, Hollister-Wagner et al. (2001) investigated the relations between exposure to violence (risk factor); aggression (maladjustment factor); and closeness to an adult, importance of religion, selfesteem, relationship competence, constructive communication, and constructive anger (protective factors). The focus on child and adolescent samples has meant that little is known about the applicability of these models to adults.

The aim of the current study was to examine the applicability of the compensatory, the risk-protective, the challenge, and the protective-protective models of resiliency for the prediction of suicidal ideation from depression and sense of belonging among older adults. The compensatory model would suggest that depression will contribute positively, while sense of belonging (psychological and antecedents) will contribute negatively to the prediction of suicidal ideation. The risk-protective model would suggest that higher levels of sense of belonging (psychological and antecedents) will reduce the effect of depression on suicidal ideation. For the challenge model, the prediction will be that suicidal ideation would have a curvilinear relationship with depression, such that moderate amounts of depression will have little of no effect on the level of suicidal ideation, compared to high levels. The protective-protective model would suggest that the level of suicidal ideation will be low for those with high levels of both components of sense of belonging (psychological and antecedents) compared to those with either sense of belonging (psychological) or sense of belonging (antecedents), and that the latter group would have less suicidal ideation compared to those with neither component of sense of be- longing (psychological or antecedents). Given that previous research has shown gender differences for depression (Kockler \& Heun, 2002) and sense of belonging (McLaren et al., 2001), the models will be tested separately for males and females.

\section{METHOD}

\section{Participants}

A total of 700 questionnaires were distributed. The final sample consisted of 351 retired older adults, representing a 50\% return rate. The sample included 221 retired women $(M$ age $=71.95, S D=8.55)$ and 130 retired men $(M$ age $=70.22, S D=6.83)$ from the state of Victoria, Australia. The majority of men were married $(80 \%)$, whereas the women were either married $(48 \%)$ or widowed $(42 \%)$. Most of the men lived in their own home with another person (69\%), whereas the women lived in their own home with another person $(43 \%)$, in a retirement village $(32 \%)$, or in their own home alone $(20 \%)$. The majority of men $(68 \%)$ and women $(71 \%)$ had at least some secondary education, and $22 \%$ of men and $13 \%$ of women had an undergraduate degree from a university. The men had been retired on average for 10.70 years $(S D=6.69)$, whereas the women had been retired for a mean of 17.28 years $(S D=14.66)$. Half of the men and women retired by choice, whereas $22 \%$ had reached retirement age, and $18 \%$ retired due to a decline in health.

\section{Materials}

The Plain Language Statement described the research and invited the men and women to volunteer. In addition, the statement provided resources that could be accessed in the event participants experienced any distress while completing the questionnaire or after the research, including contact telephone numbers of the researchers and a general telephone counseling service. Partici- 
pants were also encouraged to speak to their doctor should they be experiencing distress.

In the demographic section of the questionnaire, participants reported their age, relationship status, postcode, highest education level achieved, previous occupation, length of time retired, and number of children and grandchildren.

The Zung Depression Scale is a 20item self-report questionnaire which measures an individual's present level of depressive thoughts and behaviors (Zung, 1965). Participants indicated the frequency with which they experienced depressive thoughts and behaviors during the past week, using a 4-point Likert scale from 1 (a little of the time) to 4 (most of the time). A high score on this scale indicates the presence of depressive symptomatology. The scale is a psychometrically sound measure with validity demonstrated by its ability to discriminate depressed and nondepressed participants (Zung, 1965). The measure is reliable, with a Cronbach's internal reliability of 82 (De Jonghe \& Baneke, 1989). Cronbach's alpha coefficient for this sample was .77.

The Sense of Belonging Instrument is a 33-item self-report measure, consisting of two separately scored scales, psychological state and antecedents (Hagerty \& Patusky, 1995). The 18 questions of the psychological subscale assessed an individual's experience of feeling valued, needed, and accepted and the perception of fit or connectedness within a system or environment (e.g., "In general, I don't feel a part of the mainstream of society," "I feel like a piece of a jigsaw puzzle that doesn't fit into the puzzle"). The 15 questions of the antecedent subscale assessed antecedents or precursors to sense of belonging, such as energy for involvement, potential, and desire for meaningful involvement (e.g., "It is important to me that I am valued or accepted by others," "I don't have the energy to work on being a part of things"). Respondents were asked to reflect on the past month, and to give ratings on a 4-point Likert scale $(1=$ strongly disagree; $4=$ strongly agree), with higher scores indicating a greater sense of belonging. Previous research has shown the instrument to be a valid and reliable measure. The scale's construct validity is supported by the inter-scale correlation of the psychologi$\mathrm{cal}$ and the antecedents subscales $(r=.45)$. The test-retest reliability coefficients for the instrument have been measured as $r=.84$ for psychological state and $r=.66$ for antecedents over an 8-week period. The internal consistency coefficient (alpha) was also acceptable; .93 , for psychological state and .72 for antecedents (Hagerty \& Patusky, 1995). In terms of the present research, alphas were .90 and .78 for the psychological and antecedent subscales, respectively.

The number of protective factors was derived from the scores for sense of belonging (psychological) and sense of belonging (antecedents). To obtain this score, the mean scores for sense of belonging (psychological) and sense of belonging (antecedents) were used to recode these scores. Individuals with scores at or above the group's mean scores were considered to be protected by the appropriate measures, and were scored 1. All other individuals were scored 0 . Following this, the recoded scores for sense of belonging (psychological) and sense of belonging (antecedents) were combined to provide the number of protective factors score. Thus participants had either 0 protective factors, 1 protective factor (either component of sense of belonging: psychological or antecedent), or 2 protective factors (both components of sense of belonging: psychological and antecedent).

Participants' level of suicidal ideation was assessed using the General Health Questionnaire's suicide subscale (Goldberg \& Hillier, 1979). Participants indicated the frequency with which they experienced suicidal thoughts and behaviors during the past week. Responses to the seven items were made on a 4-point Likert scale $(1=$ not at all; $4=$ much more than usual), with higher scores indicating the presence of more suicidal ideation. The suicide subscale has been used extensively as a screening tool and in previous suicide research, and has been found to be reli- 
able and valid, with a correlation of $r=.73$ between subscale scores and independent clinical measures of suicidality (Goldberg \& Hillier, 1979). Reliability analysis for the current research indicated an alpha of .77 .

\section{Procedure}

Ethics approval was sought and received from the university's Human Research Ethics Committee. Participants were recruited from community clubs (e.g., senior citizens, bowling clubs), retirement villages, nursing homes, parks, and via home help agencies. Prospective participants were given a verbal description of the study, and those interested in participating were given a questionnaire package. The completion of the questionnaire was voluntary and participants gave informed consent upon reading the cover letter and then agreeing to participate. Participants completed the questionnaire either at the place of recruitment or at home and returned it via the postage paid envelope provided. Participants with sight impairments were assisted as needed. The order of the surveys were counterbalanced and randomly distributed.

\section{Data Analysis}

The compensatory, risk-protective, challenge, and protective-protective models were tested using the multiple regression methods proposed by Garmezy et al. (1984) and others (e.g., Hollister-Wagner et al., 2001). All models were tested separately for males and females. The compensatory, riskprotective, and challenge models were tested in the same analysis by regressing the outcome measure (suicidal ideation) on the risk factor (depression), the relevant protective factor (either the psychological or antecedent component of sense of belonging), risk factor $\times$ protective factor, and risk factor $\times$ risk factor. Significant prediction by both the risk and protective factors indicates support for the compensatory model. Significant predictions by risk factor $\times$ protective factor and risk factor $\times$ risk factor indicate support for the risk-protective and challenge models, respectively.

The protective-protective model was tested by regressing the outcome measure (suicidal ideation) on the risk factor (depression), number of protective factors, risk factor $\times$ number of protective factors, risk factor $\times$ risk factor, and risk factor $\times$ risk factor $\times$ number of protective factors. Significant contribution to the prediction of the outcome measure by the risk factor $\times$ number of protective factors variable indicates support for the protective-protective model.

As noncentered cross-product terms are not interactions, centered scores (i.e., the actual score minus the mean score) were used in all regression analyses. An added advantage of using centered scores is that it reduces problems of multicollinearity of product terms (Cohen \& Cohen, 1983).

\section{RESULTS}

\section{Descriptive Scores, Correlations Between Measures, and Gender Difference}

Table 1 presents the mean and standard deviation scores for depression, sense of belonging (psychological), sense of belonging (antecedents), number of protective factors, and suicidal ideation for males and females. It also shows the results of the analyses for differences between males and females on these measures. Females reported significantly higher levels of suicidal ideation than males. In relation to suicidal ideation, 62 males (48\%) and 141 females (64\%) endorsed at least one question on the scale. Further, 22\% of males and $23 \%$ of females endorsed at least one of the questions pertaining to death.

Table 1 also shows the inter-correlations between the study measures for males and females separately. For both groups, the results indicate that higher levels of both components of sense of belonging and more 
TABLE 1

Correlations Between Depression, Sense of Belonging (Psychological), Sense of Belonging (Antecedents), Number of Protective Factors and Suicidal Ideation, and Descriptive Statistics and Gender Differences for these Measures

\begin{tabular}{|c|c|c|c|c|c|}
\hline & 1 & 2 & 3 & 4 & 5 \\
\hline \multicolumn{6}{|c|}{ Correlations } \\
\hline 1. Depression & - & $-.58^{* *}$ & $-.37^{* *}$ & $-.46^{* *}$ & $.47^{* *}$ \\
\hline 2. Sense of Belonging & & & & & \\
\hline (Psychological) & $-.47^{* *}$ & - & $.50^{* *}$ & $.78^{* *}$ & $-.49^{* *}$ \\
\hline 3. Sense of Belonging & & & & & \\
\hline (Antecedents) & $-.25^{\star *}$ & $.58^{* *}$ & - & $.71^{* *}$ & $-.30^{* *}$ \\
\hline $\begin{array}{l}\text { 4. Number of protective } \\
\text { factors }\end{array}$ & $-32^{* *}$ & $77^{\text {** }}$ & $74^{* *}$ & _- & $-34^{* *}$ \\
\hline 5. Suicidal Ideation & $.34^{* *}$ & $-.51^{* *}$ & $-.38^{* *}$ & $-.36^{* *}$ & - \\
\hline \multicolumn{6}{|c|}{ Mean (standard deviation) scores \& gender differences from $\mathrm{t}$ test } \\
\hline Females $(n=221)$ & $34.56(8.21)$ & $57.92(9.25)$ & $44.50(5.24)$ & $1.04(0.85)$ & $9.67(3.01)$ \\
\hline Males $(n=130)$ & $33.67(7.38)$ & $58.52(9.21)$ & $45.56(4.97)$ & $0.95(0.85)$ & $8.82(2.55)$ \\
\hline$t$ test $(d f=349)$ & 1.02 & 0.58 & 1.87 & 0.87 & $2.69^{* *}$ \\
\hline
\end{tabular}

Note. For the correlations, the values above the diagonal are for females, and the values below the diagonal are for males.

${ }^{*} p<.05 ;{ }^{* *} p<.01$

protective factors are related to lower levels of depression and suicidal ideation. In addition, higher levels of depression are related to higher levels of suicidal ideation.

Testing the Compensatory, RiskProtective, and Challenge Models with Sense of Belonging (Psychological) as the Protective Factor for Females

Table 2 shows the results of the analysis for testing the compensatory, risk-protective, and challenge models with sense of belonging (psychological) as the protective factor. As will be noticed, there were significant predictions by depression, sense of belonging (psychological), and depression $x$ sense of belonging (psychological). The significant predictions by both depression and sense of belonging (psychological) indicate support for the compensatory model, while the significant prediction by depression $x$ sense of belonging (psychological) indicates support for the risk-protective model.
Figure 1 shows the depression $\mathrm{x}$ sense of belonging (psychological) interaction effect. For clarity, the regression equation used for the graph was derived from an analysis in which suicidal ideation was regressed on depression, sense of belonging (psychologi$\mathrm{cal}$ ), and depression $\mathrm{x}$ sense of belonging (psychological). The regression equation for this prediction was as follows: suicidal ideation $=9.33+(0.07 \times$ depression $)+(-0.10 \times$ sense of belonging [psychological] $)+(-0.01$ $\times$ depression $\times$ sense of belonging [psychological]). For the graph, the effects of depression and sense of belonging (psychological) on suicidal ideation were plotted at two points: high and low. High and low values for both these measures were $+1 S D$ and $-1 S D$ of their centered mean of zero. As will be noticed in Figure 1, suicidal ideation is similar in women with high levels of sense of belonging (psychological) regardless of level of depression. In contrast, for women with low levels of sense of belonging (psychological), level of depression is important such that high levels of depression are associated with 
TABLE 2

Results of the Analyses for Testing the Compensatory, Risk-Protective, and Challenge Models Involving Sense of Belonging (Psychological) and Sense of Belonging (Antecedents) as Protective Factors for Females

\begin{tabular}{|c|c|c|c|c|}
\hline & $b$ & $S E$ & $\beta$ & $t$ \\
\hline \multicolumn{5}{|c|}{ Protective factor $=$ Sense of Belonging (Psychological) } \\
\hline Depression & 0.06 & 0.03 & .16 & $2.21^{*}$ \\
\hline Sense of Belonging (Psychological) & -0.10 & 0.02 & -.29 & $4.32^{* * *}$ \\
\hline Depression $\times$ Sense of Belonging & -0.01 & 0.00 & -.18 & $2.05^{*}$ \\
\hline \multirow[t]{2}{*}{ Depression $\times$ Depression } & 0.00 & 0.00 & .13 & 1.45 \\
\hline & \multicolumn{4}{|c|}{$R^{2}=.35\left[F(4,216)=29.50^{* * *}\right]$} \\
\hline \multicolumn{5}{|c|}{ Protective factor $=$ Sense of Belonging $($ Antecedents $)$} \\
\hline Depression & 0.10 & 0.03 & .27 & $3.88^{* * *}$ \\
\hline Sense of Belonging (Psychological) & -0.08 & 0.04 & -.14 & $2.25^{*}$ \\
\hline Depression $\times$ Sense of Belonging & 0.00 & 0.01 & -.02 & 0.33 \\
\hline \multirow[t]{2}{*}{ Depression $\times$ Depression } & 0.01 & 0.00 & .28 & $3.18^{* * *}$ \\
\hline & \multicolumn{4}{|c|}{$R^{2}=.30\left[F(4,216)=22.85^{\text {***}]}\right.$} \\
\hline
\end{tabular}

${ }^{*} p<.05 ;{ }^{* *} p<.01 ;{ }^{* * *} p<.001$

high levels of suicidal ideation, and low levels of depression are associated with low levels of suicidal ideation.

\section{Testing the Compensatory, Risk- Protective, and Challenge Models with Sense of Belonging (Antecedents) as the Protective Factor for Females}

Table 2 also includes the results of the analysis for testing the compensatory, riskprotective, and challenge models in which sense of belonging (antecedents) served as the protective factor. Here there were significant predictions by depression, sense of belonging (antecedents), and depression $\times$ depression. The significant predictions by both depression and sense of belonging (antecedents) indicate support for the compensatory model. The significant prediction by depression $\times$ depression implies support for the challenge model.

Figure 2 shows the depression $\times$ depression interaction effect. The regression equation used for the graph was derived from an analysis in which suicidal ideation was regressed on depression and depression $\times$ de- pression. The regression equation for this prediction was as follows: suicidal ideation $=$ $9.08+(0.12 \times$ depression $)+(0.014 \times$

depression $\times$ depression). Using this equation, the values for suicidal ideation for centered depression scores ranging from -15 (minimum score) to 30 (maximum score) were computed for the graph. As shown, low to moderate levels of depression were not associated with an increase in suicidal ideation, whereas very low levels of depression were associated with a slight increase in suicidal ideation, and higher levels of depression were associated with a substantial increase in suicidal ideation.

\section{Testing the Protective-Protective Model for Females}

Table 3 shows the analysis for testing the protective-protective model. As shown, there were significant predictions by depression, number of protective factors, and depression $\mathrm{x}$ depression. The nonsignificant interaction between depression and number of protective factors fails to support the protective-protective model. 


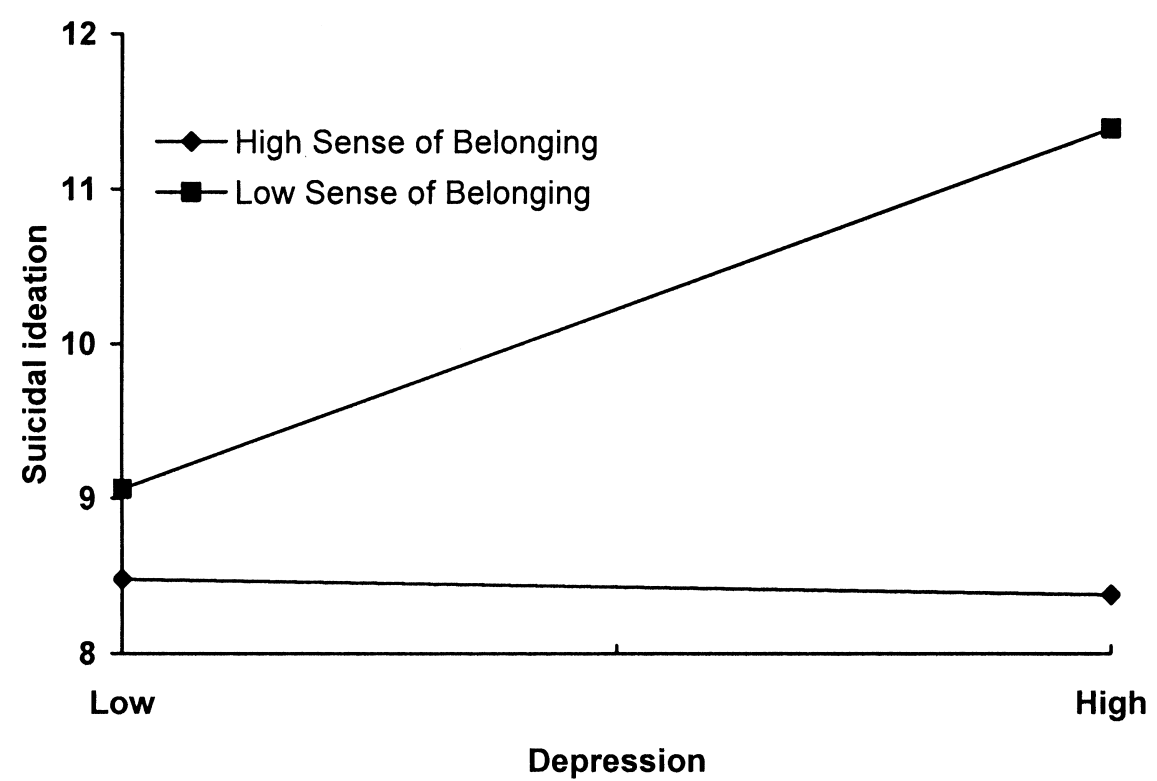

Figure 1. Suicidal ideation as a function of high and low depression, and high and low sense of belonging (psychological) for females.

Testing the Compensatory, RiskProtective, and Challenge Models with Sense of Belonging (Psychological) as the Protective Factor for Males

Table 4 shows the results of the analysis for testing the compensatory, risk-protective, and challenge models with sense of belonging (psychological) as the protective factor. As will be noticed, there were significant predictions by sense of belonging (psychological), and depression $\times$ sense of belonging (psychological). The significant prediction by depression $\times$ sense of belonging (psychological) indicates support for the risk-protective model.

Figure 3 shows the depression $\mathrm{x}$ sense of belonging (psychological) interaction effect. For clarity, the regression equation used for the graph was derived from an analysis in which suicidal ideation was regressed on depression, sense of belonging (psychological), and depression $\times$ sense of belonging (psychological). The regression equation for this prediction was as follows: suicidal ideation $=8.53+(0.04 \times$ depression $)+(-0.10 \times$ sense of belonging [psychological] $)+(-0.01$ $\times$ depression $\times$ sense of belonging [psychological]). As will be noticed in Figure 3, the result is similar to that described previously for females, in that suicidal ideation is similar in men with high levels of sense of belonging (psychological) regardless of level of depression. In contrast, for men with low levels of sense of belonging (psychological), suicidal ideation is high when levels of depression are high.

\section{Testing the Compensatory, Risk- Protective, and Challenge Models with Sense of Belonging (Antecedents) as the Protective Factor for Males}

Table 4 also includes the results of the analysis for testing the compensatory, riskprotective, and challenge models in which sense of belonging (antecedents) served as the protective factor. Here there were significant predictions by depression and sense of belonging (antecedents). The significant predictions by both depression and sense of belonging (antecedents) indicate support for the compensatory model. No support was ev- 


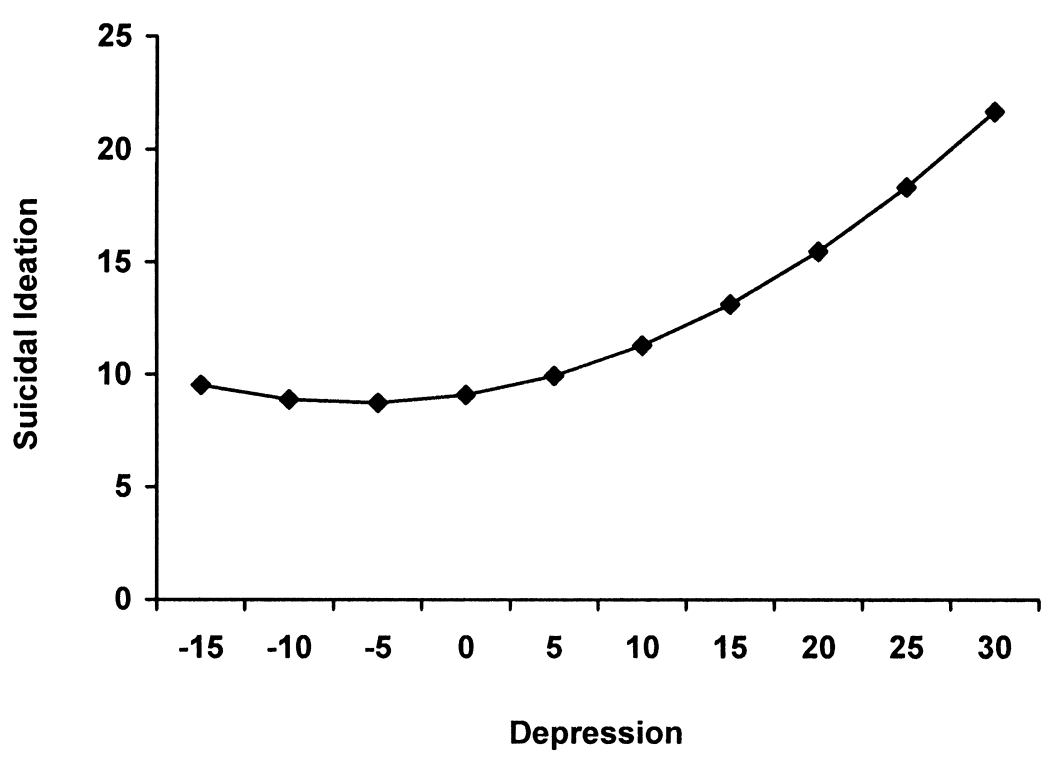

Figure 2. Suicidal ideation as a function of depression $\times$ depression for females.

ident for the risk-protective or challenge models for males.

\section{Testing the Protective-Protective Model for Males}

Table 5 shows the analysis for testing the protective-protective model. As shown, there were significant predictions by depression and number of protective factors. The nonsignificant interaction between depression and number of protective factors fails to support the protective-protective model.

\section{DISCUSSION}

The aim of this study was to investigate the applicability of four resiliency models to suicidal ideation among older adults, with the risk factor being depression, and the protective factors being the two dimensions of sense of belonging to the community (psychological and antecedents). Initial correlations indicated that both dimensions of sense of belonging were negatively associated with depression and suicidal ideation, and that depression was positively associated with sui-

TABLE 3

Results of the Analysis for Testing the Protective-Protective Model for Females

\begin{tabular}{lrrrr}
\hline & \multicolumn{1}{c}{$b$} & $S E$ & $\beta$ & $t$ \\
\hline Depression & 0.09 & 0.04 & .25 & $2.28^{*}$ \\
Number (\#) of protective factors & -0.57 & 0.27 & -.16 & $2.15^{*}$ \\
Depression $\times \#$ of protective factors & 0.00 & 0.03 & .01 & 0.08 \\
Depression $\times$ Depression & 0.01 & 0.00 & .28 & $3.18^{* *}$ \\
Depression $\times$ Depression $\times \#$ of protective factors & 0.00 & 0.00 & .01 & 0.18 \\
& \multicolumn{4}{c}{$R^{2}=.30\left[F(5,214)=18.54^{* * *}\right]$} \\
\hline
\end{tabular}

$$
{ }^{*} p<.05 ;{ }^{* *} p<.01 .{ }^{* * *} p<.001
$$


TABLE 4

Results of the Analyses for Testing the Compensatory, Risk-Protective, and Challenge Models Involving Sense of Belonging (Psychological) and Sense of Belonging (Antecedents) as Protective Factors for Males

\begin{tabular}{|c|c|c|c|c|}
\hline & $b$ & $S E$ & $\beta$ & $t$ \\
\hline \multicolumn{5}{|c|}{ Protective factor $=$ Sense of Belonging (Psychological) } \\
\hline Depression & 0.03 & 0.03 & .08 & 0.96 \\
\hline Sense of Belonging (Psychological) & -0.11 & 0.02 & -.39 & $4.51^{* * *}$ \\
\hline Depression $\times$ Sense of Belonging & -0.01 & 0.00 & -.23 & $2.75^{* *}$ \\
\hline \multirow[t]{2}{*}{ Depression $\times$ Depression } & 0.00 & 0.00 & .10 & 1.18 \\
\hline & \multicolumn{4}{|c|}{$R^{2}=.34\left[F(4,1250)=16.12^{* * *}\right]$} \\
\hline \multicolumn{5}{|c|}{ Protective factor $=$ Sense of Belonging $($ Antecedents $)$} \\
\hline Depression & 0.07 & 0.03 & .19 & $2.21^{*}$ \\
\hline Sense of Belonging (Psychological) & -0.16 & 0.04 & -.32 & $3.91^{* * *}$ \\
\hline Depression $\times$ Sense of Belonging & -0.01 & 0.01 & -.14 & 1.69 \\
\hline \multirow[t]{2}{*}{ Depression $\times$ Depression } & 0.01 & 0.00 & .13 & 1.49 \\
\hline & \multicolumn{4}{|c|}{$R^{2}=.25\left[F(4,125)=10.21^{* * *}\right]$} \\
\hline
\end{tabular}

$$
{ }^{*} p<.05 ;{ }^{* *} p<.01 ;{ }^{* * *} p<.001
$$

cidal ideation. Taken together, these findings are consistent with the view that depression and sense of belonging are risk and protective factors, respectively, as they relate to suicidal ideation.

For women and men, it was evident that the risk-protective model was supported, when sense of belonging (psychological) was the protective factor. These results suggest that a high level of feeling that they are valued by others and integrated within the community reduces the effects of depression on suicidal ideation among aging men and women. For women only, results regarding sense of belonging (psychological) also supported the compensatory model. This result suggests that for women, the strength of the association between suicidal ideation and depression is reduced when sense of belonging is considered. Although research has indicated that males report lower levels of sense of belonging than females (McLaren et al., 2001), and the relationship between sense of belonging and depression is stronger for females than males (Hagerty et al., 1996), these results indicate that if men experience feeling valued and important in the community, then depression is no longer a risk factor for suicidal ideation.

When sense of belonging (antecedents) was the protective factor, the compensatory model was supported for both men and women. Results indicate that for men and women, the positive association between depression and suicidal ideation is reduced by their levels of motivation and desire to belong to the community. In women only, the challenge model was also supported. This result indicated that low to moderate levels of depression were associated with low levels of suicidal ideation. Very low levels of depression were associated with a slight increase in suicidal ideation, although these levels of suicidal ideation were still very low. Consequently, this result is not of clinical significance. It was also evident that high levels of depression were associated with an escalation in suicidal ideation. This relationship has been supported consistently in the literature (Awata et al., 2005; Preville et al., 2005).

Results failed to support the protective-protective model for males or females. This model predicted that suicidal ideation would be low for those people who had high 


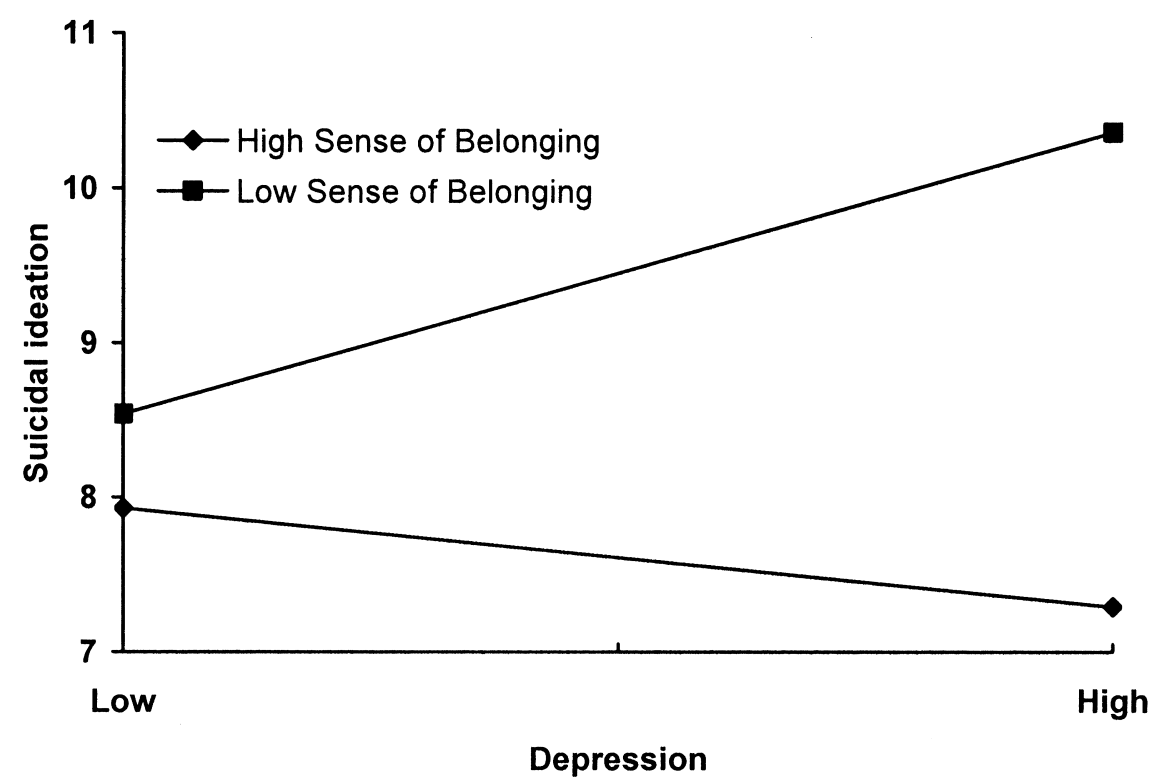

Figure 3. Suicidal ideation as a function of high and low depression, and high and low sense of belonging (psychological) for males.

levels of both components of sense of belonging, compared to people who were high in only one component, and these people, in turn, would have lower levels of suicidal ideation than those who were low on both components of sense of belonging. Clearly, men and women who reported being motivated and having a desire to belong in combination with actually reporting a feeling of being valued and fitting within the community indicated similar levels of suicidal ideation compared with men and women who reported only one component or neither component of sense of belonging. It is possible that the protective-protective model was not supported due to the similar constructs being measured by the two components of sense of belonging. Future research may support this model by investigating other protective factors, including marital status (Duberstein et al., 2004), social support (Schwarzer, 1992), physical health (Waern et al., 2002), and reasons for living (Linehan, Goodstein, Nielsen, \& Chiles, 1983).

TABLE 5

Results of the Analysis for Testing the Protective-Protective Model for Males

\begin{tabular}{lrrrr}
\hline & \multicolumn{1}{c}{$b$} & $S E$ & $\beta$ & $t$ \\
\hline Depression & 0.11 & 0.05 & .32 & $2.42^{*}$ \\
Number (\#) of protective factors & -0.87 & 0.32 & -.29 & $2.74^{* *}$ \\
Depression $\times \#$ of protective factors & -0.05 & 0.04 & -.17 & 1.41 \\
Depression $\times$ Depression & 0.01 & 0.00 & .13 & 1.11 \\
Depression $\times$ Depression $\times \#$ of protective factors & 0.00 & 0.00 & .01 & 0.07 \\
& \multicolumn{2}{c}{$R^{2}=.23$} & {$\left[F(5,124)=7.19^{* * *}\right]$} \\
\hline
\end{tabular}

${ }^{*} p<.05 ;{ }^{* *} p<.01 .{ }^{* * *} p<.001$ 
Overall, the present research supports the theory that establishing and maintaining relatedness, in particular a sense of belonging, with other people, objects, environments, and society is important for survival, development, and growth (Hagerty, LynchSauer, Patusky, \& Bouwsema, 1993). It is evident that interventions targeted at enhancing sense of belonging among aging adults, especially those who are suffering from depression, need to be developed and evaluated. This may prove challenging for researchers and those who work with older adults. There is evidence to suggest that simply engaging in activities with others is not related to older people experiencing a sense of belonging (Bailey \& McLaren, 2005). Research needs to focus on how sense of belonging can be enhanced among aging people. The results of this study suggest that if this can be achieved, suicidal ideation can be reduced. Given the link between suicidal ideation and suicide attempts and completions (Mireault \& de Mann, 1996), the outcomes of such interventions may be fewer suicides among older people.

While the findings in this study provide insight in to the ways in which sense of belonging operate as a protective factor against depression in relation to suicidal ideation, several limitations of the study need to be acknowledged. First, as the study used correlation analysis on data collected concurrently, it is not possible to infer any causal relationship between variables. In this study, all data were collected through self-report from the same source. Thus a second limitation is the possibility that the results may have been confounded by common method variance. Third, half of the people who accepted a questionnaire failed to return it to the researchers. It is impossible to know how those who did not complete the questionnaire differed from those who did. Perhaps those who refused to participate in the study were more likely to have suicidal ideation, depressive symptoms, or lessened sense of belonging. Fourth, a convenience sample, rather than a randomly selected sample, was used. As a result, the current sample was more highly educated than the aging Australian population (Australian Bureau of Statistics, 1999), and underrepresented by men and women who lived in their own home alone (Australian Bureau of Statistics, 2005). Further, most of the men in the sample were married. There is much evidence to suggest that marriage is a protective factor for older men (Duberstein et al., 2004; Peters \& Liefbroer, 1997). Hence, the sample itself is a limitation. Future research in this area needs to include more widowed and divorced men in particular, as they are most at risk of suicide. Fifth, the study is based on a sample from one state in Australia. The extent to which these results can be generalized to older adults residing elsewhere, particularly internationally, is unknown. Sixth, the current study examined suicidal ideation as the adjustment factor, rather than attempted or completed suicide. Although suicidal ideation is a predictor of suicide attempts and completions (Mireault \& de Mann, 1996), it is important to recognize that suicidal ideation does not lead to suicide in the majority of people. Thus, we must be cautious in generalizing the results of this study to people who attempt or complete suicide. Finally, it should be acknowledged that older adults themselves have the propensity to be a limitation in studies. Older adults frequently have impediments, such as cognitive decline, and therefore have difficulty understanding the meaning of questions and recalling information such as symptoms and experiences (Thompson, Futterman, \& Gallagher, 1988).

In summary, both components of sense of belonging were shown to be protective factors, although the components operated in different ways. The role of sense of belonging also varied somewhat according to the gender of the participant. Intervention programs are needed that enhance sense of belonging among aging adults, as is research that carefully evaluates the effectiveness of such interventions. The goal of this future work is to reduce suicide among older people, especially men. 


\section{REFERENCES}

Australian Bureau of Statistics. (1999).

Australian social trends 1999: Educational profile of Australians. Canberra, Australia: Author.

Australian Bureau of Statistics. (2004). Suicides: Recent trends, Australia (3309.0.55.001). Canberra, Australia: Author.

Australian Bureau of Statistics. (2005). Australian social trends: Housing for older adults. Canberra, Australia: Author.

Awata, S., Seki, T., Koizumi, Y., Sato, S., Hozawa, A., Omori, K., ET AL. (2005). Factors associated with suicidal ideation in an elderly urban Japanese population: A community-based, crosssectional study. Psychiatry \& Clinical Neurosciences, 59, 327-336.

Bailey, M., \& McLaren, S. (2005). Physical activity alone and with others as predictors of sense of belonging and mental health in retirees. Aging and Mental Health, 9, 82-90.

Besser, A., \& Priel, B. (2005). Interpersonal relatedness and self-definition in late adulthood depression: Personality predispositions and protective factors. Social Behavior and Personality, 33, 351-382.

Brewer, M. B. (1991). The social self: On being the same and different at the same time. Personality and Social Psychology Bulletin, 17, 475482.

Chubb, N. H., \& Fertman, C. I. (1992). Adolescents' perceptions of belonging in their families. Families in Society: The Fournal of Contemporary Human Services, 73, 387-394.

Cohen, J., \& Cohen, P. (1983). Applied multiple regression analysis for the behavioral sciences (2nd ed.). Hillside, NJ: Erlbaum.

De Jonghe, J.F.M., \& Baneke, J. J. (1989). The Zung self-rating depression scale. Psychological Reports, 64, 833-834.

Duberstein, P. R., Conwell, Y., Conner, K. R., Eberly, S., Evinger, J. S., \& Caine, E. D. (2004). Poor social integration and suicide: Fact or artifact? A case-control study. Psychological Medicine, 34, 1331-1337.

Garmezy, N., Masten, A. S., \& Tellegen, A. (1984). The study of stress and competence in children: A building block for developmental psychopathology. Child Development, 55, 97-111.

GoldberG, D. P., \& Hillier, V. F. (1979). A scaled version of the General Health Questionnaire. Psychological Medicine, 9, 139-145.

Hagerty, B.M.K., Lynch-Sauer, J., PAtusky, K. L., \& Bouwsema, M. (1993). An emerging theory of human relatedness. IMAGE: fournal of Nursing Scholarship, 25(4), 291-296.

Hagerty, B.M.K., Lynch-Sauer, J., Patusky, K. L., Bouwsema, M., \& Collier, P.
(1992). Sense of belonging: A vital mental health concept. Archives of Psychiatric Nursing, 6, 172177.

Hagerty, B.M.K., \& Patusky, K. (1995). Developing a measure of sense of belonging. Nursing Research, 44, 9-13.

Hagerty, B. M., Williams, R. A., Coyne, J. C., \& Early, M. R. (1996). Sense of belonging and indicators of social and psychological functioning. Archives of Psychiatric Nursing, 5, 235-244.

Herbert, J. (1997). Stress, the brain and mental illness. British Medical fournal, 315, 530535 .

Hollister-Wagner, G. H., Foshee, V. A., \& JACKson, C. (2001). Adolescent aggression: Models of resiliency. Fournal of Applied Social Psychology, 31, 445-466.

Kissane, M., \& McLaren, S. (2006). Sense of belonging as a predictor of reasons for living in older adults. Death Studies, 30, 243-258.

Kockler, M., \& Heun, R. (2002). Gender differences of depressive symptoms in depressed and nondepressed elderly persons. International Fournal of Geriatric Psychiatry, 17, 65-72.

Lee, R., \& Robbins, S. (1998). The relationship between social connectedness and anxiety, self-esteem and social identity. Fournal of Counselling Psychology, 45, 338-345.

Linehan, M. M., Goodstein, J. L., Nielsen, S. L., \& Chiles, J. A. (1983). Reasons for staying alive when you are thinking of killing yourself: The Reasons for Living Inventory. Fournal of Consulting and Clinical Psychology, 51, 276286.

Lockwood, K. A., Alexopoulos, G. S., \& Kaкuma, T. (2000). Subtypes of cognitive impairment in depressed older adults. American fournal of Geriatric Psychiatry, 8(3), 201-208.

Maslow, L. A. (1954). Motivation and personality. New York: Harper.

Masten, A. S., Garmezy, N., Tellegen, A., Pellegrini, D. S., Larkin, K., \& Larsen, A. (1988). Competence and stress in school children: The moderating effects of individual and family qualities. Fournal of Child Psychology and Psychiatry, 29, 745-764.

McLaren, S., Jude, B., Hopes, L. M., \& Sherritt, T. J. (2001). Sense of belonging, stress and depression in rural-urban communities. International Journal of Rural Psychology, 2. Retrieved May 1, 2004 from www.ruralpsych.com

Mireault, M., \& de Mann, A. F. (1996). Suicidal ideation among the elderly: Personal variables, stress and social support. Social Behavior and Personality, 24, 385-392. 
Peters, A., \& Liefbroer, A. C. (1997). Beyond marital status: Partner history and well-being in old age. Fournal of Marriage and the Family, 59, 687-699.

Preville, M., Boyer, R., He Bert, R., Bravo, G., \& Seguin, M. (2005). Correlates of suicide in the older adult population in Quebec. Suicide and Life-Threatening Behavior, 35, 91-105.

Pritchard, C., \& Hansen, L. (2005). Comparison of suicide in people aged $65-74$ and $75+$ by gender in England and Wales and the major Western countries 1979-1999. International Fournal of Geriatric Psychiatry, 20, 17-25.

Schulz, R., Tompkins, C. A., \& Rau, M. T. (1998). A longitudinal study of psychosocial impact of stroke on primary support persons. Psychology \& Aging, 3(2), 131-141.

Schwarzer, C. (1992). Bereavement, received social support, and anxiety in the elderly: A longitudinal analysis. Anxiety Research, 4, 287-298.

Thompson-Fullilove, M. (1996). Psychiatric implications of displacement: Contributions from the psychology of place. American Fournal of Psychiatry, 153, 1516-1523.
Thompson, L. W., Futterman, A., \& Gallagher, D. (1988). Assessment of late-life depression. Psychopharmacology Bulletin, 24, 577-586.

Tsuboi, S., Fukukawa, Y., NiIno, N., Ando, F., \& Shimokata, H. (2004). Age and gender differences in factors related to depressive symptoms among community-dwelling middleaged and elderly people. Fapanese Fournal of Psychology, 75, 101-108.

Waern, M., Rubenowitz, E., Runeson, B., Skoog, I., Wilhelmson, K., \& Allebeck, P. (2002). Burden of illness and suicide in elderly people: Case-control study. British Medical Journal, 324, 1355-1363.

Yang, J., Haley, W. E., \& Small, B. J. (2002). The role of mastery and social resources in the associations between disability and depression in later life. Gerontologist, 42, 807-813.

ZuNG, W.W.K. (1965). A self-rating depression scale. Archives of General Psychiatry, 12, $63-70$.

Manuscript Received: August 11, 2005

Revision Accepted: May 10, 2006 